\title{
La psicosis del psiquiatra: la vida y obra del Dr. Kandinsky.
}

\author{
Psychosis of a Psychiatrist: life and work of Dr. Kandinsky.
}

\author{
Ekaterina Kokoulina a ${ }^{\text {, Tiburcio Angosto }}{ }^{\text {. }}$.
}

${ }^{a}$ Psicóloga, residente de Psicología Clínica, Servicio de Psiquiatría del Complejo Hospitalario Universitario de Vigo, España, ${ }^{b}$ Psiquiatra, Jefe de Servicio, Servicio de Psiquiatría del Complejo Hospitalario Universitario de Vigo, España.

Correspondencia: Ekaterina Kokoulina Cherevach (ekaterina.kokoulina@yahoo.es)

Recibido: 20/03/2011; aceptado: 19/07/2011

RESUMEN: Se realiza una revisión de la vida así como de las principales aportaciones clínicas de uno de los autores más influyentes de la Psiquiatría rusa, Víctor Kandinsky. Desafortunadamente, su influencia apenas ha trascendido fuera de las fronteras de su país de origen. El propósito principal de este trabajo es dar a conocer su obra. Al mismo tiempo, su trabajo sobre fenómenos psicopatológicos se contextualiza en la propia experiencia vital que marcó los principales intereses psiquiátricos del autor. Además de la observación detallada de la sintomatología de los pacientes que trató, el autor practicó la autoobservación de su experiencia personal para la descripción de determinados fenómenos psicopatológicos tales como las pseudoalucinaciones y las experiencias de automatismo mental que padeció durante periodos de su vida.

A pesar de la gran influencia que Kandinsky ha tenido en el análisis fenomenológico de estos síntomas psiquiátricos, el conocimiento de su obra se basa en gran medida en traducciones de sus originales. Creemos que esta es la primera vez en España que se realiza un trabajo que se basa en las aportaciones originales del autor.

PALABRAS CLAVE: Kandinsky, psiquiatra ruso, pseudoalucinaciones, automatismo mental.

\begin{abstract}
This article aims at reviewing the life and main clinical contributions of one of the most influential authors of Russian Psychiatry, Victor Kandisnky. Unfortunately, little of his influence has extended beyond the limits of his home country. The main purpose of this paper is to present his work. At the same time, his research on psychopathological phenomena is placed in the context of his own life experiences, which marked the author's main fields of interest. In addition to the detailed observation of his patients' symptomatology, the author performed the self-observation of his personal experience to describe certain psychopathological phenomena such as pseudohallucinations and experiences of mental automatism he suffered during different periods of his life.

Despite the enormous influence that Kandinsky had in the phenomenological analysis of these psychiatric symptoms, the knowledge of his work is mostly based on translations of his writings. We believe this is the first time in Spain that work is done based on the author's original contributions. KEY WORDS: Kandinsky, Russian psychiatrist, pseudohallucinations, mental automatism.
\end{abstract}

\section{Introducción}

Víctor Kandinsky (1849-1889), uno de los psiquiatras más influyentes en la segunda mitad del siglo XIX, pertenece a los fundadores de la psiquiatría rusa (1). El Síndrome de Automatismo Mental, descrito por Kandinsky, lleva su nombre y aparece en las descripciones clínicas de pacientes de todo el mundo (2). Kandinsky fue el primero en investigar y realizar una descripción sistemática del fenómeno de 
pseudoalucinaciones, basándose en numerosos casos clínicos de su propia práctica médica (3). Entre otras aportaciones de Kandinsky destaca su estudio sobre la inimputabilidad legal de los enfermos mentales, que sentó las bases del desarrollo de la psiquiatría legal rusa. Sin embargo, y a pesar de las numerosas aportaciones de este autor, su vida y obra sigue siendo poco conocida fuera de las fronteras de la antigua URSS.

Pero la particularidad más interesante de las aportaciones de Víctor Kandinsky radica en el hecho de que el sujeto fundamental de sus observaciones fuera él mismo. Atormentado por un largo proceso psicótico que finalmente habría acabado con su vida, Kandinsky se dedicó a la meticulosa autoobservación y la descripción de los fenómenos que le sucedían, convirtiendo su enfermedad mental en una valiosa aportación a la psiquiatría.

Resulta sorprendente la escasez de datos que han trascendido las fronteras rusas. Pocas de las obras de Kandinsky han sido traducidas integras a otros idiomas. Las escasas publicaciones que mencionan a este autor, se basan en traducciones y en los artículos que abordan el tema de las pseudoalucinaciones, y no las obras originales de Kandinsky, e incluso algunos autores lo han confundido con su pariente lejano el pintor Wassily Kandinsky.

El propósito de nuestro trabajo es sacar a la luz al que creemos una de las figuras más influyentes de la psiquiatría del siglo XIX y la repercusión que su trágica y controvertida vida tuvo en su obra psiquiátrica, que hasta ahora había permanecido en la sombra. Pensamos que es la primera vez que se publica en español un artículo en el que se hace una revisión de sus artículos psiquiátricos desde su lengua vernácula.

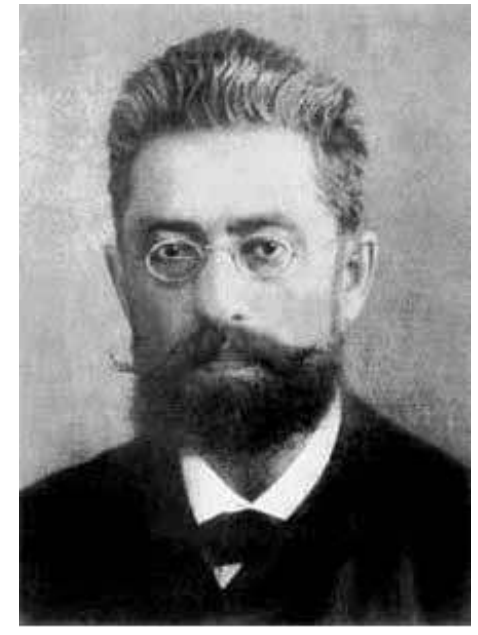

1.Víctor Kandinsky

\section{Vida y Obra de Víctor Kandinsky}

Víctor Kandinsky nació el 24 de marzo de 1849 (6 de abril, según el calendario Gregoriano instaurado en el 1918) en un pequeño pueblo de Biankin, situado en la región de Nerchinsk, en el sur de Siberia, en el seno de una familia acomodada y culta. Su padre, Hrisanf Kandinsky, exitoso y conocido comerciante de pieles, tenía en gran estima el desarrollo intelectual y la educación de sus 10 hijos, motivo por el cual en el 1863, a la edad de 14 años, Víctor abandona su pueblo natal y se traslada a Moscú, donde continúa su educación. Durante sus años de colegio, Víctor demuestra ser un alumno 
ORIGINALES Y REVISIONES

extraordinario. Sus brillantes calificaciones académicas le permiten matricularse en 1867 en la Facultad de Medicina de la Universidad de Moscú sin pasar los exámenes de selectividad. De los 22 alumnos de su promoción de enseñanza media, Víctor es el único que decide estudiar medicina, completamente convencido de estar realizando su verdadera vocación (3).

La época universitaria de Kandinsky está marcada por enormes dificultades económicas del joven médico, que se había visto obligado a pasar temporadas de hambre, subsistiendo con lo mínimo, circunstancia que no aminoró su entusiasmo académico (4). En cuarto año de carrera Víctor realiza una investigación sobre la hepatitis que obtiene reconocimiento científico a nivel nacional.

Al terminar los estudios universitarios en 1872 Kandinsky empieza a ejercer en el hospital Vremennaya Bolnitsa de Moscú (a partir de 1878 pasa a demonizarse Vtoraya Gradskaya Bolnitsa), que en aquel momento contaba con 7 facultativos. Desde los comienzos de su ejercicio profesional, Kandinsky se embarca en varios proyectos de investigación y participa activamente en la revista "Meditsinskoe Obozrenie" desde el momento de su fundación, llegando a realizar 31 publicaciones en el período de 1874 a 1876. Las aportaciones de Kandinsky eran especialmente valiosas por su dominio de varias lenguas extranjeras, hecho que le permitió introducir en la práctica clínica rusa las novedades occidentales en cuestiones de diagnóstico y tratamiento de distintas enfermedades somáticas. De las 31 publicaciones de Kandinsky en aquel período, tres fueron dedicadas a la psiquiatría. El joven médico aún no tenía intención de especializarse en psiquiatría, sin embargo, sus trabajos sobre la orientación clínico-nosológica demuestran un profundo conocimiento de las obras de Kahlbaum, Krafft-Ebing y otros psiquiatras de la época (3).

La labor que desempeña Kandinsky en Vremennaya Bolnitsa se ve interrumpida en el 1876 por la obligación de cumplir el servicio militar. La guerra entre Rusia y Turquía estaba a punto de estallar. Kandinsky es destinado a la base naval de Nikolaev, situada en el Mar Negro el 23 de septiembre de 1876, donde empieza a ejercer como médico militar en el hospital de la Marina. El 6 de enero de 1877, recibe la orden de embarcar en el buque de guerra "Gran Duque Konstantin", que parte inmediatamente hacia el lugar de batalla. En el transcurso de la primera batalla naval y tras una fuerte explosión, impresionado por los acontecimientos que sucedían a su alrededor, se tira al mar con la intención de quitarse la vida. Los datos existentes nos permiten situar el inicio de la enfermedad mental de Kandinsky en los días previos al intento de suicidio, aunque no existe información exacta sobre su estado mental en aquel momento. Por las cartas de sus compañeros, que aún se conservan en los archivos $(3,5)$, se podría deducir que padecía un episodio depresivo severo durante varios meses previos a la batalla naval, y que se encontraba impresionado por la dureza de la guerra, para la cual no estaba en absoluto preparado, pero los datos conocidos de su enfermedad apuntan a que Kandinsky había 
sufrido un episodio psicótico agudo pocos días antes de la batalla, y que el intento de quitarse la vida habría sido una consecuencia de dicho proceso psicótico previo, más que desencadenante del mismo.

$\mathrm{El}$ intento de suicidio resulta frustrado. Kandinsky es rescatado con vida, y desembarcado para la evaluación de su estado mental en el hospital de la base naval de Nikolaev. Poco después, es trasladado al Hospital Psiquiátrico de St.Petersburgo para su tratamiento y recuperación. Es acompañado en todo momento por una joven enfermera, Elizaveta Freimut, que había cuidado de él desde el inicio de su enfermedad. La pareja no se separará nunca más desde entonces. Se casan el 1 de septiembre de 1878 y permanecen juntos hasta el trágico final de Kandinsky, que su esposa comparte poco tiempo después.

La recuperación del primer episodio psicótico de Kandinsky resulta largo y duro. Permanece ingresado en el hospital psiquiátrico durante 11 meses. Tras ser dado de alta en abril de 1878, realiza un viaje por Europa, durante el cual sufre exacerbaciones de la sintomatología psicótica, que no había llegado a remitir por completo. Al volver, se ve obligado a ingresar de nuevo. Esta vez, el ingreso dura 8 meses y termina con la remisión total.

Liberado del servicio militar por su trastorno mental, Kandinsky se dedica en pleno al ejercicio de la medicina. El episodio que había sufrido despierta su interés por las enfermedades mentales. En 1880 publica su primer trabajo sobre las alucinaciones, basado en la estricta autoobservación y descripción de su propia sintomatología, así como en la evocación artificial de las alucinaciones, con su análisis retrospectivo posterior. Este trabajo da comienzo a la segunda etapa profesional de

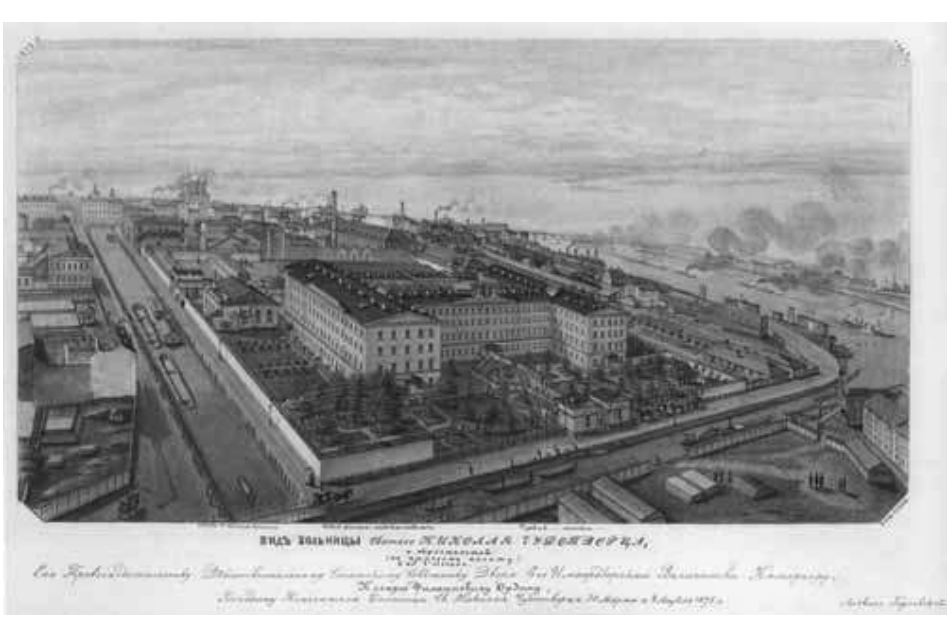

1.Hospital psiquiátrico Peterburgskaya psikhiatricheskaya bolnitsa Nikolaja Chudotvortsa (San Nicolás El Milagroso) en St.Petersburgo (fuente: http://psychiatry.spsma.spb.ru/kafedra/basis/pryajka.htm)
Kandinsky, dedicada por completo al ejercicio de la psiquiatría. Un año después de la publicación de su obra "Estudio de las alucinaciones", empieza a ejercer como psiquiatra en el hospital psiquiátrico Peterburgskaya psikhiatricheskaya bolnitsa Nikolaja Chudotvortsa (San Nicolás El Milagroso) 
ORIGINALES Y REVISIONES

en St.Petersburgo. Su inagotable dedicación a los pacientes, motivada quizás por su propia sintomatología, es destacada por varios de sus colegas (3). Kandinsky pasa gran parte de su tiempo conversando con los numerosos pacientes ingresados, llegando a mantener entrevistas diarias y centrándose sobre todo en los síntomas pseudoalucinatorios, los cuales parecían ser fenómenos muy frecuentes entre sus enfermos.

Ejerció como médico-psiquiatra del Hospital San Nicolás El Milagroso durante los ocho últimos años de su vida, desde 12 de noviembre de 1881 hasta su muerte en 1889. Varios trabajos sobre Kandinsky señalan que en 1885 fue nombrado director del hospital. Sin embargo, revisando los archivos históricos de San Nicolás El Milagroso, podemos afirmar que esto no es cierto. El cargo del director fue ocupado por O.A.Chechott, desde 1881 hasta 1901 (6).

Tras cuatro años de remisión total, sufre un nuevo episodio psicótico en 1883 (7), precedido por una fuerte depresión. Tras un corto ingreso psiquiátrico, es dado de alta en condiciones de "recuperación parcial", tal y como consta en su informe de alta (3). El nuevo episodio no impidió que siguiera ejerciendo su labor psiquiátrica con éxito. Las investigaciones de esta época le consagran como uno de los psiquiatras más influyentes de la segunda mitad del siglo XIX $(1,3,4)$. El fenómeno de Automatismo Mental le proporciona el reconocimiento científico a nivel mundial (2). No menos destacable es su trabajo sobre las pseudoalucinaciones. A pesar de no ser el pionero en introducir este concepto, es el primer autor que delimita y estudia exhaustivamente el fenómeno pseudoalucinatorio basándose en los numerosos ejemplos de su práctica clínica y en la revisión de todos los trabajos previos (8), hecho que sitúa a Kandinsky como uno de los autores más destacados en el estudio de las pseudoalucinaciones.

Víctor Kandinsky puso fin a su vida el 3 de septiembre de 1889, a la edad de 40 años. Atormentado por los síntomas depresivos, que siempre habían precedido un nuevo episodio psicótico, ingirió una gran cantidad de opio, tras lo cual siguió trabajando $(7,9)$. Hasta sus últimos segundos su vida estuvo dedicada al estudio de la psiquiatría. Dos de sus monografías más importantes, "Sobre las pseudoalucinaciones" y "Acerca de la inimputabilidad", fueron publicadas por su esposa a título póstumo. Poco después de publicarlas, atormentada por la pérdida de Víctor, Elizaveta decidió acabar con su propia vida.

\section{Enfermedad mental de Kandinsky}

¿Hasta qué punto la trayectoria vital y profesional de Kandinsky estuvo influida por el trastorno mental que padecía? Sabemos a ciencia cierta que gran parte 
de sus aportaciones están basadas en la autobservación de su propia sintomatología psicótica. Tal y como describe él mismo: "Habiendo tenido la desgracia de padecer la locura alucinatoria durante dos años, y habiendo conservado tras mi recuperación la capacidad de evocar voluntariamente ciertas alucinaciones, pude, naturalmente, observar en mi mismo algunas condiciones de aparición del delirio sensorial" (10).

La historia clínica de Kandinsky como paciente, datada de 1883 y conservada en el Archivo Histórico de St Petersburgo, contiene pocos datos de interés $(3,4)$. Sabemos que su madre era una mujer sana, que el parto de su hijo Víctor había sido normal, y que la infancia de Kandinsky había transcurrido sin enfermedades ni conductas extrañas. Kandinsky no refería tener hábitos perjudiciales; no fumaba, no consumía alcohol ni otros tóxicos. Su esposa Elizaveta le describía como "emocionalmente estable, sin cambios ni arrebatos temperamentales" y "escrupuloso en el cumplimiento de sus obligaciones"(3). Refiere que su marido había tenido un único intento autolítico, en el transcurso del primer episodio psicótico. Como causa precipitante, ambos señalan la sobrecarga de trabajo y los esfuerzos mentales excesivos.

Las notas de seguimiento clínico son pobres en detalles, y las entrevistas con su mujer, aunque valiosas desde el punto de vista histórico, no aportan información relevante. En estas entrevistas, Elizaveta Kandinskaya niega categóricamente cualquier tipo de antecedentes familiares de enfermedades mentales, lo que trajo una gran confusión histórica. Rokhlin hace públicas las historias clínicas de varios parientes de Kandinsky, ingresados en asilos psiquiátricos con patología mental severa. Estos documentos están conservados en el Archivo Histórico de St Petersburgo (3).

Kandinsky describe su propia enfermedad mental en el trabajo "Zur Lehre von den Hallucinationen", escrito en 1880 y publicado en alemán en el $\mathrm{N}^{\circ} 11$ (1881) de Archiv für Psychiatrie und Nervenkrankheiten (10). Este trabajo es anterior al estudio sobre las pseudoalucinaciones, razón por la cual, en él todos los fenómenos experimentados por Kandinsky son denominados "alucinaciones". Al parecer sufría de alucinaciones que afectaban todos sus sentidos, a excepción del gusto, siendo las más frecuentes y vívidas las visuales y las somáticas. Las alucinaciones olfativas eran relativamente raras, y era difícil distinguirlas de las impresiones reales debido a que su sentido de olfato era muy pronunciado. "En muchos casos" - describe- "era complicado distinguir las alucinaciones auditivas de las percepciones auditivas reales, ya que en un asilo el paciente oye tantos sonidos procedentes de todas partes, voces, charlas de todo tipo, que es difícil distinguir lo real de lo ficticio" (10).

Describe numerosas sensaciones de tacto y presión, así como percepciones de alteración del equilibrio corporal y la posición del cuerpo en el espacio. Los 
ORIGINALES Y REVISIONES

objetos parecían girar alrededor de su cuerpo. "El suelo parece volar bajo mis pies, las paredes vuelan o se parten en dos. En ocasiones noto con el ojo derecho que una parte de la pared se mueve hacia arriba, y el ojo izquierdo registra que otra parte de la misma se mueve hacia abajo, lo que produce una sensación muy dolorosa de que el cerebro se está rompiendo" (10). Kandinsky consideró que todas aquellas alucinaciones que producían la impresión de movimiento de objetos o de alteración de la posición del propio cuerpo en el espacio eran producto de una disfunción debida a la falta de nutrición del cerebelo $(10,11)$.

Durante el primer mes de su enfermedad Kandinsky no sufrió alucinaciones. Describe que sus síntomas predominantes durante aquel período inicial fueron la actividad mental irregular, el delirio intelectual, la frenética sucesión de engaños perceptivos y los pensamientos intrusivos e involuntarios. Siendo plenamente consciente de lo que le estaba sucediendo y de la probable evolución de su enfermedad, permanecía sumido en un profundo estado que describió como una mezcla de tristeza, apatía y desesperanza, y probablemente por esa razón fue diagnosticado de melancolía. Describe las razones de su estado melancólico como "nuevas condiciones de vida, la interrupción de la actividad habitual, la separación de los familiares y amigos, y finalmente la conciencia de mi enfermedad y sus posibles consecuencias, tales como la debilidad de espíritu" (10). El rechazo voluntario de la comida llegó a producirle anemia. Había observado que las alucinaciones, que aparecieron durante el mes posterior del inicio de la sintomatología, eran la consecuencia del extremo cansancio al que estaba sometido su cerebro a causa de la actividad mental frenética. Tal y como describe él mismo: "las alucinaciones empezaron y fueron aumentando de variedad y viveza después de un agotamiento significativo del cerebro, en parte por la estimulación procedente de la esfera de la actividad intelectual, y en parte por una fuerte anemia, resultado de la inanición deliberada" (10). El primer período de su enfermedad fue denominado por Kandinsky como "delirio intelectual". La mayor sorpresa fue darse cuenta de la escasa influencia que tenía el delirio intelectual sobre el carácter de las alucinaciones: sólo una décima parte de las alucinaciones tenía relación directa con el delirio previo. Sin embargo, afirmaba que era común la relación inversa: las personas que sufren de alucinaciones tratan de explicar y racionalizar su naturaleza y contenido, especialmente si creen en su realidad, lo que propicia la aparición de ideas delirantes, estrechamente relacionadas con las alucinaciones. "Yo tampoco podía evitarlo", afirmó.

No había, afirmaba, una clara distinción entre los períodos de sueño y de vigilia: las alucinaciones pueden llegar a ser tan reales que el paciente piensa que está soñando. "Durante el período de mi enfermedad, mis sueños no se diferenciaban por su viveza de lo que vivía estando despierto, no podía decidir si lo que había experimentado era real o soñado" (10). 
En general, las alucinaciones que sufría no eran incongruentes con su nivel cultural y educación, y solamente una pequeña parte de ellas tenía relación con los engaños perceptivos o las ideas intrusivas que invadían su mente. Sin embargo, durante los últimos meses de su primer episodio psicótico, las alucinaciones tenían tan poco que ver con su persona que Kandinsky llegó a pensar que eran comunicadas por alguna especie de inducción eléctrica desde las mentes de otros pacientes que le rodeaban.

Había observado que durante los períodos del despertar de la actividad mental y el inicio del pensamiento, las alucinaciones palidecían, llegando incluso a desaparecer por completo por un tiempo, hasta que la atención se centraba en ellas nuevamente. El estado más favorable para la aparición de las alucinaciones, describía Kandinsky, era de suspensión total de la actividad, tanto mental como física. Durante los períodos de remisión, conseguía provocarse los estados alucinatorios mediante la supresión de toda estimulación, tanto la exterior como mental, con la finalidad de realizar un análisis posterior. Describe, con todo detalle, las alucinaciones visuales que se producían estando con los ojos abiertos o cerrados. En el primer caso, "la imagen se proyectaba sobre la superficie del suelo, el techo o las paredes, o apareciendo en el espacio, ocultando los objetos que se hallaban detrás. En algunos casos, el entorno real desaparecía por completo y era reemplazado por unos momentos por otro entorno diferente. De pronto me encontraba transportado a la orilla del mar, en la orilla opuesta se prolongaba una cadena de montañas, y el paisaje no era como una pintura de óleo, sino real". Con los ojos cerrados, las alucinaciones aparecían en forma de objetos materiales que le rodeaban, imágenes simples y complejas. "Con el tiempo - describía - me acostumbré a las alucinaciones visuales, pero eso no me supuso ninguna sensación de opresión, más bien, me sirvió incluso para pasar el tiempo" (10).

Como consecuencia de estas observaciones, Kandinsky había desarrollado un método terapéutico para paliar las alucinaciones, en aquel entonces novedoso, que guarda una estrecha relación con la rehabilitación cognitiva actual para la esquizofrenia, de eficacia ampliamente demostrada. Había observado que la aparición de las alucinaciones tenía un efecto supresor no solamente del delirio intelectual, sino también de la actividad intelectual en general. Esta observación fue clave para darse cuenta de la importancia del trabajo intelectual en la contención de la sintomatología sensoperceptiva. Tal y como describe, "sin una intensa intervención de la voluntad, mis alucinaciones probablemente se hubieran vuelto estables, y mi actividad intelectual, sin recibir alimento, se hubiera apagado definitivamente. Una vez acostumbrado a la presencia de las alucinaciones, empecé a leer. Al principio era una tarea dificil, ya que las alucinaciones auditivas me molestaban continuamente en el trabajo y las imágenes visuales se interponían entre el libro y los ojos. Con el tiempo, me acostumbre a leer, lo que distraía mi atención de las 
ORIGINALES Y REVISIONES

alucinaciones. El retomar la actividad intelectual, las alucinaciones se volvieron más pálidas y menos frecuentes, aunque desaparecieron por completo meses más tarde. Esto me permite concluir que el trabajo intelectual resulta de gran ayuda para la curación de las alucinaciones" (10).

En cuanto a su propio diagnóstico, Kandinsky se diagnostica de "locura primaria" (12), modificándolo posteriormente y denominándolo "psicosis primaria delirante alucinatoria". Además de argumentar el diagnóstico, critica a los psiquiatras que le habían diagnosticado de melancolía, señalando la incompatibilidad entre la melancolía y las alteraciones sensoperceptivas y el delirio.

Las conclusiones que extrae Kandinsky del proceso de la autoobservación se describen en su trabajo "Zur Lehre von den Hallucinationen" (10), y se amplían en la monografía "Sobre las pseudoalucinaciones" $(13,14)$ :

1. Las alucinaciones no son nunca la expresión de una actividad agitada de la esfera espiritual, sino por el contrario una expresión del agotamiento de la misma, esto es, de la corteza de la parte anterior del cerebro. Los períodos del delirio intelectual no coinciden con los de las alucinaciones. Con el despertar de la actividad espiritual las alucinaciones se vuelven más tenues y desaparecen. Las actividades espirituales correspondientes a las fuerzas del enfermo contribuyen en gran medida a mitigar las alucinaciones.

2. El mecanismo y las condiciones para el surgimiento de las alucinaciones hipnagógicas y las de los enfermos mentales son similares.

3. Las alucinaciones se diferencian de las imágenes de recuerdo y de las fantasías, por muy vivas que sean estas últimas, en la percepción de objetividad que le es propio.

4. Las alucinaciones dependientes de las excitación de los nervios de los órganos de los sentidos se caracterizan por su simpleza; las alucinaciones visuales periféricas poseen además a menudo la particularidad de moverse en círculos, así como la de seguir los movimientos de los ojos.

5. La influencia de los recuerdos y del contenido del delirio intelectual sobre las alucinaciones es muy reducida. Incluso entre los enfermos mentales las imágenes fantásticas no tienen por qué llevar siempre a alucinaciones.

\section{Caso Clínico M. Dolinin}

No cabe duda que el caso clínico más famoso descrito por Kandinsky en su obra "Acerca de las pseudoalucinaciones", denominado "Caso Dolinin", es una detallada y pormenorizada descripción de su propia enfermedad mental $(3,4,7)$. Aparte de las obvias coincidencias entre Dolinin y el mismo Kandinsky en el curso 
de cada episodio y la sintomatología descrita, llama la atención la profundidad de detalle con la que narra el caso. La descripción de los pensamientos íntimos del paciente, de su estado mental durante los experimentos con tintura de opio, de las particularidades de los fenómenos sensoperceptivos experimentados, excede con creces lo posible en un caso clínico normal. Por último, el estilo narrativo de Kandinsky al describir el caso, categórico y personal, hace imposible suponer que lo que está describiendo es un caso de un paciente. Vamos a citar un fragmento del Caso Dolinin, tal y como lo describe Kandinsky $(13,14)$ :

M.Dolinin, médico militar de 38 años, sufría de PARANOIA HALLUCINATORIA ${ }^{l}$ que al principio había cursado de forma subaguda, adquiriendo finalmente un carácter más crónico. A primera vista, la sintomatología que presentaba Dolinin podía sugerir un cuadro melancólico, dados los numerosos intentos autolíticos del paciente (que más tarde resultaron ser fruto de alucinaciones auditivas e ideación delirante). El paciente se mostraba reticente a la hora de relatar sus vivencias; generalmente prefería no hablar, o respondía a las preguntas de modo tangencial. Los síntomas predominantes de Dolinin consistían en múltiples alucinaciones auditivas; además de táctiles y somáticas. Las alucinaciones visuales eran frecuentes en los momentos de exacerbación del cuadro, siendo episódicas durante el curso general. No existía ninguna predisposición hereditaria, siendo la causa de la enfermedad de Dolinin el agotamiento mental debido a las largas noches de trabajo, circunstancias vitales adversas y abuso de alcohol. Tras la remisión del primer brote, que había durado un año y medio, Dolinin había gozado de 4 años de plena salud psíquica, consiguiendo desempeñar su actividad laboral con éxito. Dolinin había comenzado a plasmar sus vivencias en un diario al final del primer brote, cuando aún no se había librado del todo de las alucinaciones auditivas.

Además del diario, Dolinin había proporcionado a Kandinsky una gran cantidad de observaciones íntimas tanto sobre las alucinaciones auditivas como sobre las pseudoalucinaciones, que resultaron ser de gran utilidad. Más tarde, Dolinin se había ofrecido voluntario para participar en la investigación de Kandinsky: mediante la administración de pequeñas dosis de opio o cánnabis, Kandinsky provocaba en el paciente las alucinaciones hipnagógicas, pidiéndole posteriormente que las describiera.

A principios de 1883, sin ninguna causa aparente, Dolinin sufrió un nuevo brote de paranoia alucinatoria, esta vez agravado con ideas delirantes persecutorias y de grandeza. Kandinsky atribuyó las causas de la recaída de Dolinin a los nuevos excesos intelectuales, y en parte, probablemente, a los experimentos con opio y

\footnotetext{
1 El diagnóstico en latín es explicado por el mismo Kandinsky como psicosis primaria delirante alucinatoria.
} 
ORIGINALES Y REVISIONES

cánnabis, que tenían por finalidad la evocación voluntaria de alucinaciones hipnagógicas (hay que mencionar que Dolinin también aprendió a provocar a voluntad las alucinaciones auditivas, muy similares a aquellas involuntarias que sufría durante el primer brote). Según describe Kandinsky $(13,14)$, durante el desarrollo del nuevo episodio, Dolinin únicamente era capaz de RECORDAR sus vivencias subjetivas, estando completamente absorto en los procesos alucinatorios e ideación delirante. Esta segunda vez el curso del episodio había sido rápido, adquiriendo insight y la capacidad de crítica a los dos meses después del inicio, y consiguiendo la remisión de las alucinaciones auditivas durante el tercer mes.

El caso clínico de M.Dolinin es rico en detalles clínicos que hacen referencia al fenómeno de automatismo mental y pseudoalucinaciones, por ello hemos decidido incluir otro fragmento, traducido literalmente de la obra de Kandinsky "Sobre las pseudoalucinaciones" (14):

Durante el primer brote de su enfermedad mental, Dolinin experimentaba alucinaciones auditivas frecuentes. Las palabras, frases, diálogos e incluso estrofas poéticas completas que llegaban a sus oídos provenían de puntos concretos del espacio externo, por ejemplo desde las paredes, de las habitaciones vecinas, de las personas que se encontraban en la misma estancia que él. Bajo la influencia de las alucinaciones auditivas, el enfermo llegó a convencerse de que estaba en manos de un ejército de torturadores camuflados, que le rodeaban en la unidad psiquiátrica bajo la apariencia de otros pacientes, médicos y personal auxiliar. Cada una de esas personas era capaz de establecer contacto con él a través de las corrientes magnéticas (Dolinin conocía el concepto de "magnetismo animal"). A través del contacto magnético, sus perseguidores eran capaces, por un lado, saber todos sus pensamientos, sensaciones y sentimientos hasta el más mínimo detalle, y por otro lado, podían transmitir a su cerebro cualquier idea o sensación que deseaban. El enfermo distinguía dos tipos de transmisiones mentales, basados en dos modos de "inducción psíquica". Por un lado, se trataba de una "imposición de pensamiento", que consistía en lo siguiente: la persona que en un momento dado se encontraba en una conexión magnética con Dolinin, de manera artificial fabricaba en el cerebro del enfermo una u otra idea tormentosa, lo cual le causaba una imagen obsesiva persistente. Por otro lado, estaba la "imposición auditiva": la persona conectada magnéticamente con Dolinin, escuchaba con esmero un sonido o ruido que quería transmitir (por ejemplo, el habla real de otra persona presente en la habitación), o incluso producía el sonido voluntariamente (hablando en voz alta, gritando y escuchando su propia producción) y de esta forma transmitía al cerebro de Dolinin sus propias percepciones auditivas. En este caso, Dolinin era capaz de distinguir las voces o la forma de hablar de las personas que aparecían en su mente, creyendo que los torturadores invisibles con frecuencia adoptaban la apariencia de los conocidos de Dolinin). 
En el trascurso de su segundo (y breve) episodio psicótico, Dolinin volvió a sufrir una gran cantidad de pseudoalucinaciones auditivas, que se presentaban tanto en forma de discurso coherente como simples sonidos y ruidos. También eran frecuentes las pseudoalucinaciones musicales (sonido de los tambores, música militar etc).

\section{Aportaciones de Kandinsky a la Psiquiatría}

Resulta sorprendente el hecho de que las novedosas aportaciones de Kandinsky no recibieron la atención merecida por parte de la comunidad científica internacional. Una de las posibles explicaciones, según nuestro punto de vista, es que la muerte prematura del psiquiatra haya impedido la publicación de una obra completa de su trabajo. La monografía "Sobre las pseudoalucinaciones" no se había publicado, como dijimos, hasta después de su muerte.

Sin duda, su principal aportación a la psiquiatría fue el concepto de pseudoalucinaciones. Si bien el término "Pseudoalucinación" fue acuñado por Hagen en 1868 (15), fue Kandinsky el primero en delimitar el concepto y proporcionar una descripción detallada del fenómeno pseudoalucinatorio, basándose en sus propias experiencias psicóticas. En 1885 Kandinsky separó de las alucinaciones verdaderas un grupo de fenómenos que él explicaba como una subcategoría patológica de las representaciones sensoriales de la memoria y de la fantasía (16). Estos fenómenos, que denominó "pseudoalucinaciones auténticas", se caracterizan por su continuidad y totalidad, espontaneidad, ausencia de conexión lógica entre las imágenes consecutivas, pasividad y receptividad, y el carácter de imposición. Un análisis más detallado del concepto de pseudoalucinaciones reúne las siguientes características $(13,14)$ :

- son extremadamente definidas y realistas, continuas, completas y estables;

- aparecen en la conciencia con toda claridad de detalles;

todas las peculiaridades de la imagen, por mínimas que sean, aparecen simultáneamente y con la misma intensidad;

- al palidecer, lo hacen en su totalidad;

- no dependen de la voluntad o de la intención de la persona;

- son siempre completamente espontáneas;

- no pueden ser modificadas ni eliminadas de la conciencia, a diferencia de las imágenes mentales normales;

- no existe conexión lógica entre varias imágenes pseudoalucinatorias consecutivas; 
ORIGINALES Y REVISIONES

- el sujeto no puede establecer una asociación entre ellas. La única excepción (según Kandinsky) se da en PARANOIA AGUDA: en este caso, las pseudoalucinaciones aparecen y se suceden con tanta rapidez que pueden crear la impresión de estar ligadas entre sí;

- el sujeto que está experimentando una pseudoalucinación no tiene la sensación de estar realizando una actividad mental por su propia voluntad, sino de ser mero receptor pasivo de la imagen visual o acústica;

- las pseudoalucinaciones de los enfermos mentales, especialmente paranoicos y melancólicos, se caracterizan por su INTRUSIVIDAD, siendo generalmente muy desagradables en su contenido;

- ciertas pseudoalucinaciones pueden convertirse en estables, interfiriendo en la capacidad cognitiva del sujeto con sus constantes apariciones (esta característica no suele darse en las personas libres de psicopatología).

El concepto de automatismo mental, descrito por Kandinsky en su monografía "Sobre las pseudoalucinaciones", permitió a Gaetan Gatian de Clerambault desarrollar su teoría del automatismo mental como primario en el desencadenamiento de la psicosis siendo el delirio y las alucinaciones secundarias. El Automatismo Mental sigue usándose bajo el nombre de Síndrome de Kandinsky-Clerambault $(2,17)$. El automatismo mental de Kandinsky, en gran parte basado en la autoobservación de su propia sintomatología, consiste en la alienación de los procesos mentales del enfermo, que empieza a vivirlos como pertenecientes a alguien más e impuestos artificialmente. Los síntomas de automatismo mental cursan con el delirio de persecución y de influencia, sentimientos de posesión (delirio de control) y transmisión de pensamiento (2).

Kandinsky fue el primer psiquiatra ruso que había propuesto en 1882 una clasificación de las enfermedades mentales $(1,3,4)$, donde incluyó el concepto de Ideofrenia (que coincide con la actual esquizofrenia). Su clasificación empezó a emplearse inmediatamente en el Hospital San Nicolás el Milagroso, haciéndose oficial en 1886.

Cabe destacar la aportación de Kandinsky a la psiquiatría forense: fue el primero en sugerir la necesidad de introducir un criterio psicológico de la imputabilidad (18). En su obra "Acerca de la inimputabilidad", publicada en 1890 a título póstumo (19), cuestiona el criterio legal utilizado en aquella época, según el cual la persona que sufría una enfermedad mental no era responsable legalmente. Por el contrario, defiende su opinión, por la que cada caso debe ser examinado individualmente de acuerdo con el diagnóstico y las circunstancias concretas, pronunciándose en contra del criterio indiferenciado de la irresponsabilidad legal. El mismo trabajo incluye la novedosa descripción del concepto de psicopatía. Su obra sigue siendo una referencia en la psiquiatría legal rusa. 


\section{Reflexión Final}

El objetivo principal del presente trabajo ha sido dar a conocer la vida y la obra del Dr. Kandinsky, poco conocido en el ámbito español hasta ahora y a veces erróneamente citado, a pesar del hecho de que autores como K. Jaspers o H. Rorschach utilizaran sus descripciones de las pseudoalucianciones para apoyar sus clasificaciones de las pseudopercepciones. Aun reconociendo su contribución a la psiquiatría moderna, Kandinsky había sido definido como "sujeto extraordinariamente imaginativo", y su trabajo como "obra literaria" (20). Tras la investigación exhaustiva, hemos encontrado pocas referencias a su trabajo en las publicaciones nacionales e internacionales, aunque es de destacar el trabajo de Lerner y Witztum (2003), en el que se presenta una revisión biográfica de la vida de Kandinsky, así como sus principales aportaciones (7).

Si bien es cierto que, como señala Berrios (12), la obra de Kandinsky es principalmente la descripción de sus propias alucinaciones, no sería apropiado dejar de reconocer que fue el precursor de conceptos clave en la psiquiatría como el automatismo mental o el fenómeno pseudoalucinatorio.

Con todo, el trabajo de Kandinsky puede plantear algunos interrogantes. ¿Hasta qué punto son científicamente válidas las descripciones de su propia sintomatología que realiza un enfermo mental, aún poseedor del conocimiento psiquiátrico? ¿De qué manera había influido Kandinsky en la posterior conceptualización de pseudoalucinaciones? Todas estas cuestiones se abordarán en profundidad en nuestro siguiente trabajo, que tratará específicamente sobre el concepto y las particularidades del fenómeno pseudoalucinatorio, tal y como lo había descrito Víctor Kandinsky.

\section{BIBLIOGRAFÍA:}

(1) Snezhnevsky AB. Kandinsky VKh: Biograficheskii ocherk (Kandinsky VKh: ensayo biográfico). En: Kandinsky VKh. O psevdogallutsinatsiakh. (Sobre las pseudoalucinaciones). Moscú: Medgiz, 1952.

(2) Mikirtumov BE, Ilichev AB. Istoriya izuchenia sindroma psihkicheskogo automatizma (Sydrome of mental automatism: history of discovery). Nauchno-meditsinskii vestnik Tsentralnogo Chernozemia 2009; 35:124-32.

(3) Rokhlin LL. Zhizn i tvorchestvo vydajuschegosia russkogo psikhiatra V.Kh. Kandinskogo (Vida y obra del famoso psiquiatra ruso V.Kh.Kandinsky). Moscú: Meditsina, 1975.

(4) Shoifet MS. Sto velikikh vrachei (Cien médicos excepcionales). Moscú: Veche, 2006.

(5) Sabashnikov MV. Vospominaniia. (Memorias). Moscú: Kniga; 1983.

(6) Kofman IS, Tochilov VA. Psikhiatricheskaya bolnitsa Sv. Nikolaya Chudotvortsa v dosovetskii period (Hospital Psiquiátrico San Nicolás el Milagroso: período presoviético). Cátedra de Psiquiatría 
y Adicciones de la Academia Estatal de Medicina de San Peterburgo Mechnikov [en formato electrónico, consultado 14-12-2010]: Disponible en: http://psychiatry.spsma.spb.ru/kafedra/basis/pryajka.htm.

(7) Lerner V, Witztum E. Victor Kandinsky. MD: psychiatrist, researcher and patient. Hist Psychiatr, 2003; 14 (1): 103-111, 035138.

(8) Villagrán JM, Luque R. Pseudoalucinación: un análisis crítico. Rev. Asoc. Esp. Neuropsiq. 1994; XIV (50): 391-402.

(9) Rothe, A. Dr. Med. W.Ch.Kandinski. Necrolog. Allgemeine Zeitschrift für Psychiatrie und psychisch-gerichtloche Medicin 1890, 46: 550.

(10) Kandinsky V. Zur Lehre von den Hallucinationen. Arch Psychiat Nerven 1881; 11: 453-64.

(11) Ireland WW. German Retrospect. Journal of Mental Science 1881; 27:426-34.

(12) Berrios GE, Dening TR. Pseudohallucinations: a conceptual history. Psychol Med 1996; 26 : $753-63$.

(13) Kandinsky VKh. O psevdogallutsinatsiakh. Kritiko-klinicheskii etud. (About pseudohallutinations. Critical-clinical etude). Sankt-Petersburg: Izdanie EK Kandinskoi, 1890.

(14) Kandinsky VKh. O psevdogallutsinatsiakh. (Sobre las pseudoalucinaciones). Moscú: Meditsinskaya kniga, 2007.

(15) Hagen FW. Zur Theorie der Hallucination. Allgem. Zeitschr. Fur Psychiat. 1868; 25: 1-113.

(16) Angosto, T. Fenomenología y Psiquiatría (sin publicar).

(17) Lerner V, Kapstan A, Witztum E. The Misidentification of Clerambault's and KandinskyClerambault's Syndromes. Can J Psychiat 2001; 46: 441-43.

(18)Pervomaisky VB. K 100-letiyu knigi V.Kh. Kandinskogo "K voprosu o nevmeniaemosti” (100 aniversario del libro de V.Kh.Kandinsky “Acerca de la inimputabilidad”). Zh Nevropatol Psikh 1991; 91 (9): $71-74$.

(19) Kandinsky VKh. K voprosu o nevmeniaemosti (Acerca de la inimputabilidad). Sankt-Petersburg: Izdanie EK Kandinskoi; 1890.

(20) González de Rivera JL. Pseudopercepción y Pseudoalucinación. Psiquis 1984; 5(1):1-5. 